\title{
Environmental factors and asthma hospitalization in Montreal, Canada, during spring 2006-2008: a synergy perspective
}

\author{
Alain Robichaud ${ }^{1} \cdot$ Paul Comtois $^{2}$ \\ Received: 17 June 2019 / Accepted: 26 August 2019 / Published online: 21 November 2019 \\ (C) The Author(s) 2019
}

\begin{abstract}
The aim of this study is to analyze the synergy between environmental factors (pollutant, allergenic birch pollen, weather) and its relationship with asthma hospitalization in Montreal, Canada. The data is stratified into weather types and the study restricted to spring season to limit the impact of multiple confounders. Results shows that the daily count of asthma hospitalization (spring 2006-2008) in situation of warm fronts or trowals (daily average of 3.78 counts, CI 95\% 2.954.61) was much higher $(p<0.001)$ than in other situations $(2.49$ counts, CI 95\% 2.37-2.71). Moreover, the explained variance of asthma hospitalization due to air pollution rises from about less than $7 \%$ (in the case of no stratification) to about $28 \%(R=0.53, p<0.05$ with stratification). Statistical tests for interaction and overall results point towards a synergy between environmental factors which exacerbates asthma. A new concept named frontal asthma is proposed to explain several results found here and in the open literature.
\end{abstract}

Keywords Environmental pollution · Allergenic pollen · Birch (Betula spp.) · Asthma hospitalization · Weather type · Warm front $\cdot$ Trowal $\cdot$ Frontal asthma $\cdot$ Thunderstorm asthma $\cdot$ Synergy

\section{Introduction}

Over many decades, massive evidence across the world has shown associations between outdoor environmental factors and respiratory health. These factors include atmospheric pollution (White et al. 1994; Asgari et al. 1998; Delfino et al. 2003; Shima et al. 2003; D'Amato et al. 2015), aeroallergens such as pollen and/or molds (Behrendt and Becker 2001; Dales et al. 2004, 2008; Thibaudon 2007; Sofiev and Bergmann 2013), atmospheric air mass type (Lee et al. 2012; Helbern and Cakmak 2015), or specific weather conditions related to asthma (Schappi et al. 1997; Marks and Bush

Electronic supplementary material The online version of this article (https://doi.org/10.1007/s11869-019-00744-2) contains supplementary material, which is available to authorized users.

Alain Robichaud

alain.robichaud@canada.ca

Environment and Climate Change Canada, Dorval, Canada

2 Department of geography, Université de Montréal (Canada), Montréal, Canada
2007; Mireku et al. 2009; D'Amato et al. 2015; D'Amato et al. 2016). We review the critical environmental factors below.

\section{Impact of air pollution}

Particulate matter (PM), ozone, $\mathrm{SO}_{2}, \mathrm{NO}_{2}$, and formaldehyde have been shown to have an adverse impact on respiratory health (von Ehrenstein 2002; Tamburlini 2002; D’Amato et al. 2015; ALA 2019; see Table S1 of Supplementary material for details). In Asia, France, and Iran, synergistic interaction between atmospheric pollutant and pollen grain has been demonstrated (see Okuyama et al. 2007; Sénéchal et al. 2015 and Sedghy et al. 2018, respectively). These studies are in line with previous studies proposing the neologism "polluen" (pollutant+pollen; Peltre 1998). Chemical pollution interacts with pollen in four ways: (1) it impacts the quantity of emitted pollen by plants, (2) it increases the allergenicity of the pollen released, (3) it changes the patient individual sensitivity to pollen and allergens, and (4) it favors pollen rupture or cracks in its surface liberating hundreds of small allergens or pollen fragments (size $30 \mathrm{~nm}-5 \mu \mathrm{m}$ ) which could penetrate deeper in the lungs and exacerbate respiratory problems such as asthma (Gervais 1994; Taylor and Jonsson 2004; Miguel et al. 2006; Thibaudon 2007; Laaidi et al. 2011; Sénéchal et al. 2015; Sedghy et al. 2018). 
Impact of birch (Betula spp.) pollen and its allergens

The birch (Betula spp.) pollen is studied here because (1) it is the most allergenic tree pollen (Guérin 1993), (2) it could be transported over long distances (Comtois 1996; Sofiev et al. 2006), and (3) it is characterized by one of the highest pollen production among common trees (Guérin 1993). While studying impact on respiratory health, only few studies in North America have focused on this taxon and even less on trying to appropriately control confounding factors (e.g., seasonality, weekly cycle, see Hondula et al. 2013 for details). Tiny bio-aerosols (about $1 \mu \mathrm{m}$ diameter or less) containing Bet $v 1$ antigens ${ }^{1}$ have been found in the ambient atmosphere likely due to birch pollen grain rupture (Rantio-Lehtimäki et al. 1994; Puc et al. 2016). Several researchers (Schappi et al. 1997; Chathurika et al. 2017; Wozniak et al. 2018) found that in light rain conditions, tree pollen grain releases antigens or sub-pollen inner particles contained within the grain into the atmosphere. Lacroix (2005) pointed out that laboratory work made by his team revealed that if pollen is exposed to pollution $\left(\mathrm{O}_{3}, \mathrm{NO}_{2}, \mathrm{SO}_{2}\right)$, an increase of the frequency of rupture, pollen surface cracks, or deformation of the exine is observed which facilitate the release of allergens (Traidl-Hoffmann et al. 2003). Moreover, the percentage of pollen which ruptures whenever immersed in water (or exposed to high humidity found within clouds and fog) is significantly higher if the grain has been preexposed to pollutant.

\section{Impact of meteorological conditions}

The study of environmental factors and its health impact cannot be separated from their meteorological context (Laaidi et al. 1997; D'Amato et al. 2015). The links between air mass type and asthma has been analyzed by few Canadian authors (Lee et al. 2012; Hebbern and Cakmak 2015). However, considering rather daily meteorological situations (fronts, troughs, highs and lows, etc.) as presented in here offers another point of view in analyzing the links between respiratory health and environmental conditions. Ideal weather conditions for airborne pollen release and dispersion are warm temperatures, sunny skies, dry air conditions with moderate winds (Laaidi et al. 1997; Laaidi 2001). Among studies pointing towards the impact of rapid changes in weather and asthma include Taylor and Jonsson (2004), Marks and Bush (2007), and Mireku et al. (2009) which have related sudden weather changes (thunderstorms, fronts, etc.) and asthma exacerbation whereas Schappi et al. (1997)

\footnotetext{
${ }^{1}$ This allergen is considered having the major health impact associated with birch pollen grain (de Weger et al. 2013).
}

showed the importance of rain in the release of Bet $v 1$ allergen from the birch pollen grain. Overall, three specific factors are favorable to pollen rupture and release of tiny bio-aerosols: high relative humidity (Miguel et al. 2006; Zhou 2014) or rain (Schappi et al. 1997; Chathurika et al. 2017; Wozniak et al. 2018), presence of pollution (Lacroix 2005), and the presence of enhanced atmospheric electrical field (Vaidyanathan et al. 2006). These factors can work in synergy and can occur in the atmosphere under various conditions.

\section{Focus on asthma during spring season}

This paper also focuses on asthma which is a common and chronic lung disease (Public Health Agency of Canada 2018). It is related to the atmospheric environment (D'Amato et al. 2015) and has a strong allergic component. Grossman (1997) estimated that up to $78 \%$ of asthma patients also suffer from allergic rhinitis. Bergeron and Hamid (2005) provide evidence that asthma and allergies are strongly related at any ages. The etiology of asthma is complex and presents both genetic and environmental components which interacts each other in a way which is not well understood (EPA 2008). According to the Asthma and Allergy Foundation of America, 14 of the 15 cities listed as the "most challenging places to live with asthma" have overlapping risks of ozone and ragweed pollen (EPA 2008) suggesting dangerous synergy between pollen and pollution. A key atmospheric factor to trigger asthma crisis is the presence of airborne bio-aerosols (e.g., allergens Bet $v 1$ ) which can penetrate deeper into the lungs while pollen grain (usually about $22 \mu \mathrm{m}$ of diameter for birch) is of too large dimension to penetrate the barrier of the upper respiratory track (Taylor et al. 2004). While monitoring of allergens is out of the scope of this research (no observations available in Canada yet), it is rather suggested here that estimating in each weather type the likelihood of pollen rupture (based on information from the open literature) would be more appropriate if one wants to provide a better assessment of the health risk. Sudden changes of environmental condition (air pollution, pollen, abrupt weather changes) seems to be the key in creating a synergy (Taylor and Jonsson 2004; Mireku et al. 2009; Abou Chakra et al. 2010; Sénéchal et al. 2015). This research paper will analyze asthma hospitalization counts in terms of the synergy pollen-pollution-weather type in Montreal, Canada, during the spring season 2006-2008 with special attention to the control of confounding factors. In this context, this study presented here is the first report on the impact of Betula pollen and its synergy with other environmental factors in the province of Québec, Canada. 
Fig. 1 Top: description and localization of administrative regions of Province of Quebec. Montreal island corresponds to region 06. Bottom: zoom over region 06 showing the localization of air quality monitoring station in the Montreal Island operated by the Montreal Urban Community in different sectors of the city. The ID number indicates the station identifier (see Table 1 for details). Topographic elevation above sea level is indicated by the darkness of the background (darker corresponds to higher elevation)

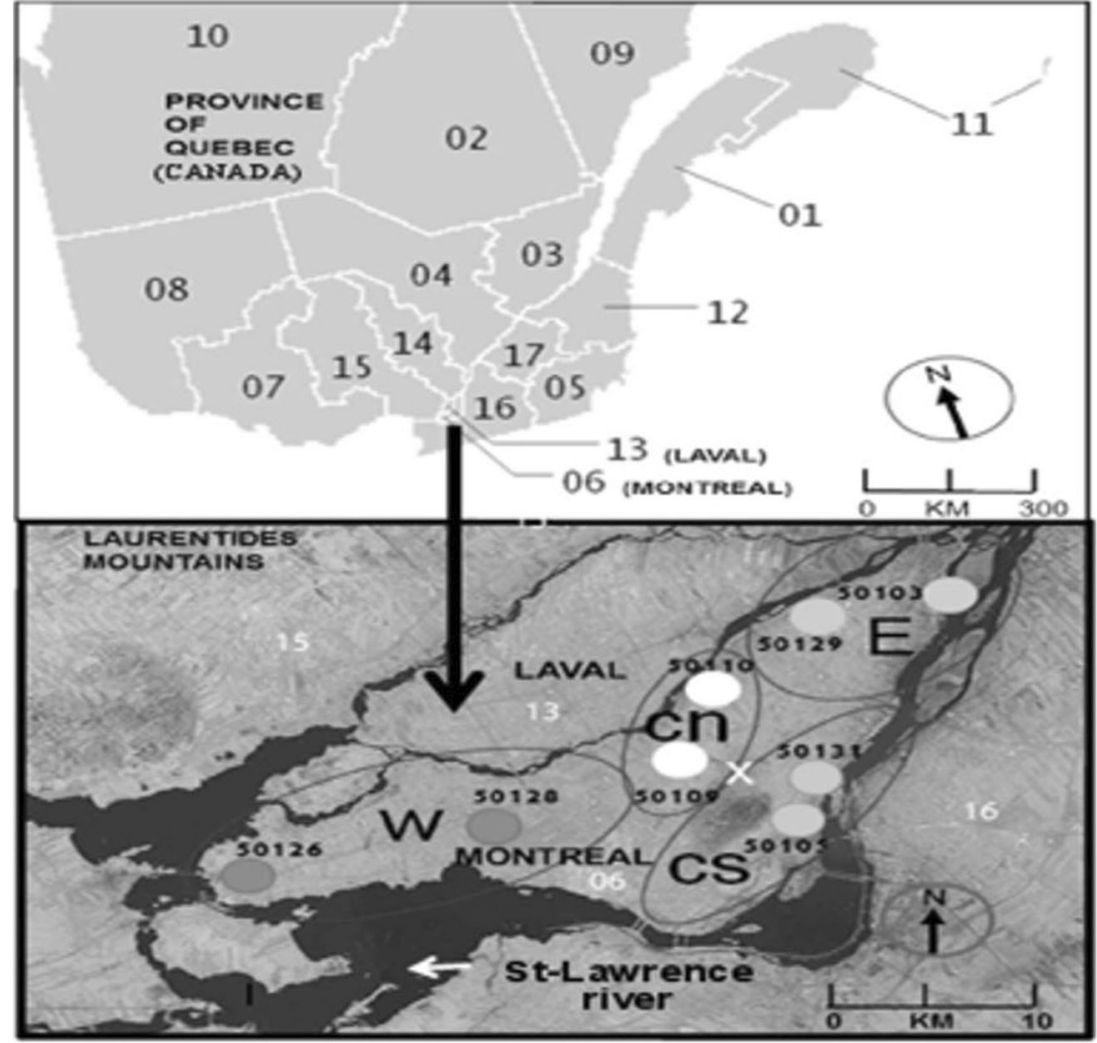

\section{Material and methods}

\section{Study area}

Montreal is an island and the largest city of the province of Québec (Canada) with roughly 1.5 million inhabitants (3.5 million for the whole metropolitan area, see www.ville. montreal.qc.ca/portal/). The daily mean temperature during the birch pollen season spans from $6.4{ }^{\circ} \mathrm{C}$ in April, $13.4{ }^{\circ} \mathrm{C}$ in May up to $19.3^{\circ} \mathrm{C}$ in June. Montreal has its heavy industrial activities including refineries in the eastern parts of the island (noted E in Fig. 1). Traffic pollution and population have both the highest density in the central parts (noted cn and cs). Finally, the western part of the island (noted w) has little industries, less traffic density, and some minor agricultural activities, and therefore presents the less frequency of days with poor air quality (Ville de Montréal 2019). Montreal is an interesting region to study the impact of birch pollen since most of it has a foreign origin (Robichaud and Comtois 2017). Therefore, health impacts due to the local pollen emitted on the island is not significant here. However, pollen of remote origin can be transported from source regions outside Montreal $^{2}$ and interact with local urban pollution. Allergic

\footnotetext{
$\overline{2}$ Birch source regions around Montreal are located mostly in regions 04,05 , 07, and 14 through 17 (see top of Fig. 1) which are mostly mountainous regions.
}

symptoms caused by long-distance transport of birch pollen have been documented for a long time (Wallin et al. 1991; Sofiev et al. 2006). Moreover, since Montreal lies within the St-Lawrence River valley, pollutants, pollen, and bio-aerosols tend to be trapped within the valley exacerbating the aerosol exposure to the population.

\section{Air pollution data}

Hourly measurement of surface $\mathrm{O}_{3}$ (ozone), $\mathrm{PM}_{2.5}$ (fine aerosols with diameter less than $2.5 \mu \mathrm{m}$ ), and $\mathrm{NO}_{2}$ (nitrogen dioxide) data were obtained from the Montreal Urban Community (http://www.ville.montreal.qc.ca) for the spring period 2006-2008 at selected site (see localization of sites in Fig. 1 and their characteristics in Table 1). An aggregate index (known as the AQHI, Air Quality Health Index) combining three pollutants $\left(\mathrm{O}_{3}, \mathrm{PM}_{2.5}\right.$, and $\left.\mathrm{NO}_{2}\right)$ is used and follows Stieb et al. (2008). In Canada, AQHI is used to describe the intensity of pollution and its impact on health. ${ }^{3}$

\section{Pollen data}

Birch (Betula spp.) pollen data was collected using a Lanzoni (VPPS) pollen trap based on the simple idea of Hirst (1952). The instrument is located at about $20 \mathrm{~m}$ above the street level

\footnotetext{
${ }^{3}$ see http://ec.gc.ca/meteo-weather/default.asp?lang=En\&n=8E7198BB-1
} 
Table 1 Description and location of the air quality monitoring station used in this study (see Fig. 1 for the location of the stations). ID stands for station identifier. AQHI stands for Air Quality Health Index (see text for more details)

\begin{tabular}{lllll}
\hline StationID & Name & Sector & AQHI available & Land use \\
\hline 50103 & Parc St-Jean-Baptiste & East & Yes & Industrial \\
50105 & Drummond & Center-South & No & Downtown \\
50109 & Décarie/Mt-Royal & Center-North & Yes & Traffic \\
50110 & Parc Pilon & Center-North & Yes & Residential \\
50126 & Ste-Anne-de-Bellevue & West & Yes & Sub-urban \\
50128 & Dorval & West & Yes & Airport \\
50129 & Rivière-des-Prairies & East & Yes & Residential \\
50131 & Hochelaga & Center-South & No & Residential/industrial \\
\hline
\end{tabular}

on the rooftop of Department of Geography of University of Montreal (see location indicated by a white $\mathrm{X}$ in Fig. 1). More details about the set-up measurement are given elsewhere (see Robichaud and Comtois 2017) and the general methodology could be found in Mandrioli et al. (1998). Note that the pollen count for a given day corresponds to a daily measurement from noon the previous day up to noon the current day. The pollen season is defined following Garcia-Mozo et al. (2002): whenever pollen concentration is greater than one grain or more for at least three consecutive days during the spring (defined here as 1st April-June 30th).

\section{Meteorological data and weather type}

All the meteorological data were taken at Montreal PierreTrudeau airport located in the western part of the island of Montreal (see location near station 50,128 in Fig. 1, latitude $45^{\circ} 28^{\prime}$ and longitude $73^{\circ} 45^{\prime}$ and at $36 \mathrm{~m}$ of elevation a.s.1) and obtained from the Meteorological Service of Canada. We consider the meteorological and pollen measurements co-located since the pollen site is representative of an area of $250 \mathrm{~km}^{2}$ (Comtois and Gagnon 1988) whereas the location of the airport is thought to be representative of the climate of the whole Montreal's island (distance pollen site to airport is about 13 $\mathrm{km})$. Weather type classification is adapted here from Robichaud and Bertrand (1993) and Heidorn and Yap (1986) and based on surface daily weather patterns (fronts, high's and low's, etc.). Daily surface weather maps at 12 UTC were obtained from the NOAA website (www.wpc.ncep.noaa.gov/ dailywxmap/index.html) or from the Meteorological Service of Canada (for 18 UTC) during the spring period of 20062008 and were used to identify the most representative weather type over the southern portion of province of Quebec (which includes Montreal) during a given day. For each weather map valid at 12 or 18 UTC (i.e., local time 8 AM or 2 PM in Montreal), a weather synoptic situation was attributed based on a simple synoptic classification system (following Table 2). The difference here with Robichaud and Bertrand (1993) is the inclusion of more synoptic features such as the trowal (through of warm air aloft), warm fronts, and surface pressure troughs. A trowal is an extension of a surface front no longer present at the surface but still active aloft and occurs when there is a wrap-up of the thermal wave (see Schultz and Vaughan 2011). On occasion whenever the synoptic weather situation changes rapidly within the day, the difference of 12 UTC and 18 UTC maps is used to capture the most representative daily weather type. Other methods to obtain a meteorological classification exist in the literature such as Lamb (1972) or Sheridan (2002) but they are based on air masses rather than daily synoptic features that gives a different perspective (climatology rather than daily weather) and has less significance in the context of near real-time forecast and synergy between environmental factors. Note that the use of stratification (e.g., weather types) blocks heterogeneity of meteorological variables within a given weather type which helps to limit the impact of confounding factors ${ }^{4}$ (Kestenbaum 2009) and provides more holistic vision than single weather variables (Heidorn and Yap 1986; Robichaud and Bertrand 1993; Sheridan 2002; Cheng et al. 2007). The validation for consistency of this weather classification has been done using principal component analysis (see the "Statistical analysis" section).

\section{Data on asthma hospitalization and control of confounding factors}

Daily data for asthma hospitalization (code 493.0, classification ICD-9-CM) was obtained for 4 different sectors of Montreal (west, center-north, center-south and east) during the spring season of years 2006 through 2008 from INSPQ (Institut National de Santé Publique, Gov. of Québec). A total of 609 asthma hospitalizations was reported during the study period. Hospitalization is an indicator of poorly controlled asthma because the disease could be prevented with proper measures (HSC 2008). Nevertheless, asthma hospitalization fluctuations are an appropriate indicator of rapid change of adverse environmental atmospheric condition although the presence of infection of the superior respiratory tract is reported to influence the decision of hospitalizing an asthmatic

\footnotetext{
${ }^{4}$ Confounding factors are source of heterogeneous variations of a given variable which seeks to explain another variable or to establish cause and effect link.
} 
patient (Lajoie et al. 1994). However, our study is performed during the spring period (where the prevalence of infection is low compared to winter, see Assaad and Cockburn 1974) so the potential bias introduced here is minimized. Note that restricting the analysis to only one season (spring) eliminates the need to control confounding factors related to seasonal variations (e.g., summer grass pollen and ragweed, spores more numerous in summer and fall). Finally, confounding factors associated with other type of asthma (such as COPD, chronic obstructive pulmonary disease, infections, bronchitis) are filtered by selecting asthma with the code 493.0. Contrary to many other studies, asthma hospitalization was preferred here to asthma emergency room visits. In fact, the former has more direct correlation and less delay for an asthma reaction following exposition to co-stressors than the latter which could be associated with delay up to 1 week as observed by Garty et al. (1998). This choice adopted here makes it easier to trace back the original cause of asthma attack and its relation to environmental conditions. One limitation of the methodology is possible misclassification of COPD as asthma particularly among smokers. However, it is believed that this does not significantly influences the results of this study since this misclassification is not expected to occur frequently.

\section{Statistical analysis}

Principal component analysis (PRINCOMP procedure of SAS®: SAS, 1989) was used to examine the relation of the weather types between each other and their proximity

Table 2 Description of synoptic meteorological classes (i.e., weather type) over Montreal with its impact on clouds and weather. The last column indicates the number of cases and frequency of each type during spring periods of years 2006-2008 (observed at 18UTC, i.e., (redundancy check) in the principal component analysis (PCA) space. PCA can be viewed as a technique that transforms the data to a new coordinate system in terms of principal component or eigenvectors (Jolliffe 2002). Figure 2 shows the validation of the classification method for weather types of Table 2 using PCA. The following loading factors were used in the PCA: afternoon maximum temperature, mid-afternoon relative humidity and dew point temperature, pressure, wind speed, wind direction, and visibility observations. As shown in Fig. 2, weather types are generally non-redundant and well distributed among four domains in the PCA space: warm and dry, warm and wet, cool and wet, and cool and dry. Some of the weather types could be re-grouped as seen later $(\mathrm{C} 1, \mathrm{C} 2, \mathrm{C} 3, \mathrm{C} 4)$ for some analyses. The possibility of pollen rupture and synergy between environmental factors will be evaluated in terms of these groups. The computation of correlation is performed using Pearson's correlation coefficient. To disentangle the role of synergy, the procedure GLM (generalized linear model) with unbalanced ANOVA (analysis of variance with sample of different sizes) of SAS ${ }^{\circledR}$ ( 2008) has been used to evaluate the significance of the differences between weather types and statistical interaction between variables. Interactions between pollen level, pollution level (ozone and fine particulate matter), and weather type (for both the current day and the previous day) are also investigated for their statistical significance. The study presented here is not a cohort study but an ecological descriptive study (see definition in NRC 1985). Variables in an ecologic analysis may be aggregate measures, environmental measures, or global measures (see for example, Robichaud 2019).

mid-afternoon). Typical origin of back-trajectories (computed from HYSPLIT tool) expressed in terms of wind direction ( $V$ variable, $S W$ south-west, $N W$ northwest, $E$ east, etc.)

\begin{tabular}{|c|c|c|c|c|}
\hline & Weather types impacting Montreal & Clouds and weather in Montreal & Origin back-trajec. & $\begin{array}{l}\text { Nb. cases and } \\
\text { frequency }(\%)\end{array}$ \\
\hline 1 & $\begin{array}{l}\text { Back of the high pressure } \\
\text { located on the eastern US seabord }\end{array}$ & $\begin{array}{l}\text { Sunny with temperature much above normal } \\
\text { (i.e., heat wave) }\end{array}$ & SW & $11(4.5 \%)$ \\
\hline 2 & Flat pressure gradient & Calm winds (temperature above normals) & $\mathrm{V}$ & $10(4.1 \%)$ \\
\hline 3 & Warm sector & $\begin{array}{l}\text { Temperature above normal (unstable situation) } \\
\text { with southerly winds }\end{array}$ & SW & $18(7.4 \%)$ \\
\hline 4 & Cold front passage & $\begin{array}{l}\text { Sudden changes of wind (speed and direction) } \\
\text { and temperatures turning colder }\end{array}$ & NW & $21(8.6 \%)$ \\
\hline 5 & Behind cold front & Northwest winds and colder & $\mathrm{N} / \mathrm{NW}$ & $5(2.1 \%)$ \\
\hline 6 & Approaching high pressure & Sunny, windy, and cool & $\mathrm{N} / \mathrm{NE}$ & $19(7.8 \%)$ \\
\hline 7 & Ridge of high pressure & Sunny skies, dry, and windy & NW/NE & $19(7.8 \%)$ \\
\hline 8 & Low pressure & Clouds and steady light rain & $\mathrm{V}$ & $34(14.0 \%)$ \\
\hline 9 & Occluded front & Unstable, cloudy, showers and turbulence & SE & $10(4.1 \%)$ \\
\hline 10 & Approaching low & Increasing cloudiness and winds & $\mathrm{NE} / \mathrm{E}$ & $13(5.3 \%)$ \\
\hline 11 & Surface through & Windy, cloudy, unstable with risk of showers & $\mathrm{W}$ & $29(11.9 \%)$ \\
\hline 12 & Warm front & $\begin{array}{l}\text { Cloudy, unstable, showers, increasing temperature } \\
\text { and humidity }\end{array}$ & $\mathrm{S}$ & $13(5.3 \%)$ \\
\hline 13 & Unclassified/missing data & Variable & $\mathrm{V}$ & $41(16.9 \%)$ \\
\hline
\end{tabular}




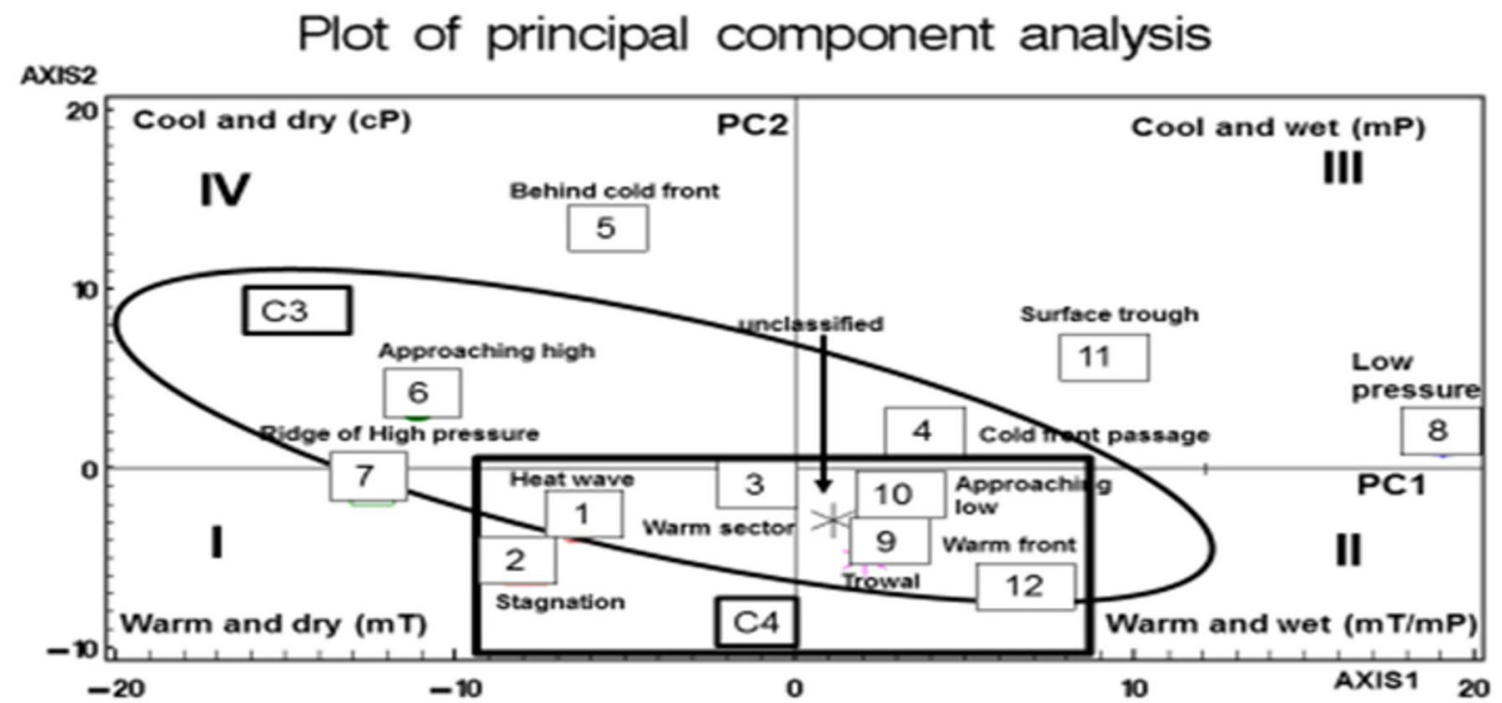

Fig. 2 Principal component analysis for the weather types. The numbers refer to the weather type of Table 2. Axis-1 is strongly dominated by the relative humidity as loading factor $(R=0.97)$. Axis- 2 is dominated by wind $(R=0.6)$ and temperature $(R=0.4)$. Together Axis-1 and Axis-2

\section{Results and discussion}

\section{Asthma hospitalization, pollen, pollution, and weather type}

Stratification according to weather type (Table 2) allows reducing the effect of meteorological variability giving rise to better association between the main atmospheric co-stressors (pollen and pollutants) and the frequency of daily hospitalization. Figure 3 a shows the total count of daily hospitalization due to asthma over the Montreal island during the pollen season versus the synoptic weather type. Results clearly show that the health risk associated with asthma is the highest in a situation of warm front (weather type 12), ridge of high pressure (weather type 7) or trowal (weather type 9) with an average of hospitalizations per day in the range 3.70-3.85 in these meteorological situations which is significantly higher $(p<$ 0.01 ) as compared with the remaining group of weather types. Interestingly, the meteorological situation usually associated with relatively high air pollution (i.e., highest values of AQHI, see Fig. 3b) that is weather type 1 (heat wave and photochemical smog situation) shows surprisingly fairly modest average hospitalization counts for asthma (Fig. 3a). In fact, an average of 2.36 hospitalizations is reported in a situation of photochemical smog during the Betula pollen season in Montreal as opposed to 3.85 for a situation of warm front (weather type 12), 3.7 for occluded front (weather type 9), and 3.79 hospitalizations as an average for ridge of high pressure (weather type 7) during the same period.

To better elucidate how environmental factors trigger asthma, we also need to include allergenic pollen into the picture. Figure $3 \mathrm{c}$ shows the average daily count of Betula pollen were found to explain $85 \%$ of the total variance. Note that the synoptic situation that could not be categorized according to Table 2 are noted unclassified on the figure. Some special groups of classes (C3 and C4) are also identified on the figure (see text for more details)

grains versus the predominant meteorological class of the current day (obtained from weather maps at 12 and 18 UTC). First, note that a large variability of Betula count is observed in each weather type as given by confidence interval (at level $95 \%)$. Second, it is interesting to note that in weather type 1 (heat wave and photochemical smog), the pollen count is very low and modest hospitalization counts are reported in this class despite the highest concentration of pollutants (i.e., higher AQHI, $p<0.05$ as shown in Fig. 3b). Consequently, this suggests that the low allergenic pollen load in weather type 1 would provide some explanation for the low hospitalization. Weather types 7 (ridge of high pressure) and 9 (occluded front) present among the highest average daily values of Betula count which is consistent with higher hospitalization rate (Fig. 3a) but not necessarily associated with the highest pollution (see Fig. 3b). Note that the maximum pollen count in a situation of high pressure (Fig. 3c) is not surprising since low relative humidity, very little precipitation, and windy afternoons are to be expected in this class and, in the latter, meteorological conditions are found optimum for pollen emission and dispersion (Laaidi et al. 1997; Helbig et al. 2004). The case of the warm front (type 12) is apparently enigmatic. It shows the highest average hospitalization count (3.85, see Fig. 3a) while presenting one of the lowest Betula count (Fig. 3c) and modest values of air pollution (Fig. 3b). To elucidate the case of warm front further, supplementary material presents a detailed case study (Table S3a, Supplementary material S2) analyzing further the link between environmental variables. Intermittent rain and higher humidity associated with warm front could explain grain pollen rupture and release of respirable Bet $v 1$ allergens from the ruptured grain triggering severe asthma (Schappi et al. 1997; Taylor et al. 2004) and 
Fig. 3 a Daily average hospitalization for asthma versus the meteorological class (i.e., weather type), b same but for daily maximum AQHI (Air Quality Health Index), c daily mean Betula count at the station UdeM versus the meteorological class. The vertical rectangles indicate interval of confidence (at the $95 \%$ level). Units for pollen are in $\mathrm{gr} / \mathrm{m}^{3}$ (grains of pollen per cubic meter)
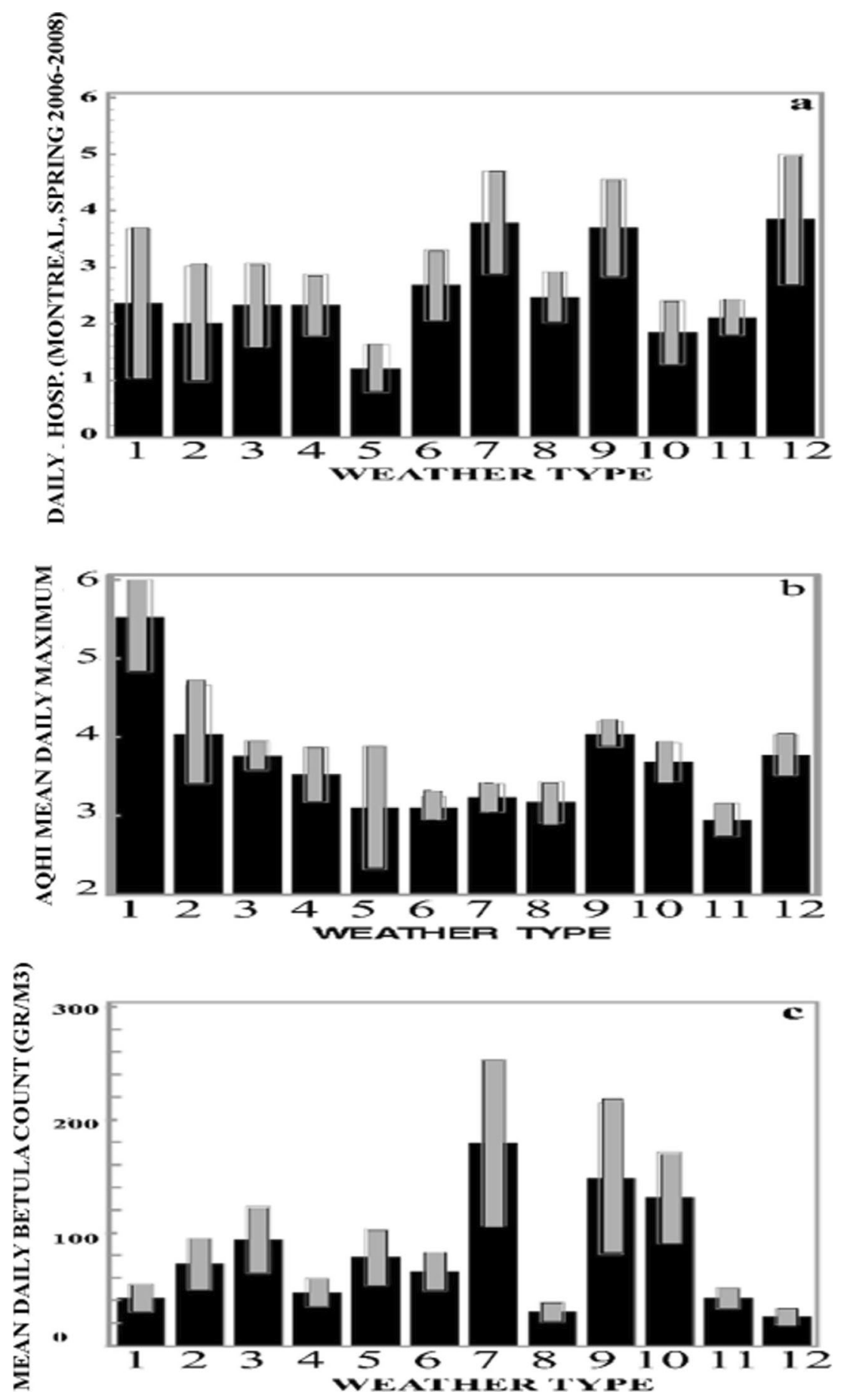

therefore a lower probability of pollen grains remaining airborne after they are ruptured. Since it has been suggested that the pollen potency varies with the weather conditions (Buters et al. 2010, 2012), the warm front situation could represent such a situation where the pollen potency would be stronger although the pollen count is lower. Conversely, some meteorological situations are associated with higher pollen (e.g., weather type 10) but with modest hospitalization rates. It is known than in type 10, (approaching low pressure system), winds bring easterly flow in Montreal (i.e., airborne pollen from the Eastern Townships region birch sources, region 5, see Fig. 1) but with rain which has not started yet so there is likely low release of airborne sub-pollen particles (containing the allergens) due to pollen rupture (Wozniak et al. 2018). On the other hand, trowals could be associated with pollen rupture as well since they are considered upper fronts so they are similar to warm fronts from a meteorological point of view. In both meteorological situations, the presence of intermittent 
rain (including cycle of wet and dry period) is common (Environment Canada 1996; Schultz and Vaughan 2011). These situations are associated to high probability of birch pollen rupture based upon independent observations (Schappi et al. 1997; Taylor et al. 2004; Zhou 2014). A case study is also presented for occluded front (Table S3b, Supplementary material S2). We will discuss pollen potency in more details later and relate it in terms of a new concept (frontal asthma: situation in which the likelihood of pollen rupture is enhanced, see below).

\section{Correlation between asthma and environmental factors}

Table 3 gives the Pearson's correlation matrix showing associations between environmental factors and asthma hospitalization rate for different sectors of the city (here we assume that a given geographical sector is rather homogeneous socioeconomically). It shows that both the Betula count and its natural logarithm (LBetu) of the current day (Lag0), the previous day (Lag1), or 2 days lag (Lag2) all have modest but statistically significant coefficient of correlation (range $R=0.12-0.26$ ) versus the daily total count of hospitalization in Montreal (all geographical sectors lumped together; see first three columns indicated by ALL). On the other hand, the correlation with ground ozone is weaker but nevertheless statistically significant (up to $R=0.15, p<0.05$ ) for $\operatorname{Lag} 1$, otherwise no significant positive correlation seems to exist between air pollution and asthma hospitalization in Montreal (all sectors combined) and for lag greater than 1 day. Note that the correlation with $\mathrm{PM}_{2.5}$ showed in the table is weak and negative $(R=-$ 0.13 ) which is not biologically plausible as a cause of hospitalization. Correlation with some other environmental

Table 3 Pearson's coefficient (correlation matrix) between the daily total count of asthma hospitalization and environmental parameters by geographical sectors $(\mathrm{N} \sim 240)$.. Betula stands for daily birch pollen count, LBetu logarithm of Betula daily count, Ozone daily maximum surface concentration, $\mathrm{PM}_{2.5}$ daily maximum surface concentration of fine particulate matter, AQHI daily maximum of the Air Quality Health Index (3-h moving average), $\mathrm{T}$ daily maximum temperature, $\mathrm{T}_{\mathrm{d}}$ mean variables is also provided in Table 3 such as current daily maximum temperature $(T)$ and dew point temperature $\left(T_{\mathrm{d}}\right)$ under Lag0, Lag1, and Lag2 scenarios, respectively. A negative correlation with temperature as obtained here was also noted in several other studies (see Lajoie et al. 1994 for a review; Garty et al. 1998 in Israel; Laaidi 2001 in Europe). The explanation seems to be related to the fact that sudden drop of temperature may be a triggering factor for asthma (see https://www.asthma.org.uk/advice/triggers/weather/) although during birch pollen season, these drops are usually not large in Montreal compared with fall or winter season. Note the coefficient of correlation up to $0.14(p<0.05)$ in the north sector (cn sector, see Fig. 1) whereas in other sectors, no correlation with ozone was found. Finally, a weak and positive correlation is obtained between pressure and asthma hospitalization in the south and east sector. Overall, similar results were obtained by Lajoie et al. (1994) for the metropolitan region of Québec City concerning correlations between emergency visits to hospital and environmental factors. Similarly, Chan et al. (2009) obtained low coefficient of correlations between asthma visits with dew point, temperature, and classical air pollutants in the city of Taipei (Taiwan) in agreement with Table 3 .

\section{Correlations stratified by grouping weather situations}

One of the strong hypothesis of this research is that the links between asthma and pollution as well as pollen is better revealed and show better associations if we compute correlation only in specific weather categories and not only by specific geographical sectors (Table 4). This stratification likely attenuates the impact of confounding factors associated with weather (which is not the case in Table 3). First, we will examine correlations

afternoon dew point temperature, WS mid-afternoon wind speed, Press mid-afternoon atmospheric pressure. In the West sector, Lag1 and Lag2 entries were found not statistically significant $(p>0.1)$ and therefore not shown. No significant correlations were found beyond Lag2 and therefore not shown. $p<0.05$ unless otherwise stated, $* 0.05 \leq p \leq 0.10$. Empty entries in the table means no significant correlation (i.e., $p>0.1$ )

\begin{tabular}{|c|c|c|c|c|c|c|c|c|c|c|c|c|c|}
\hline & $\begin{array}{l}\text { ALL } \\
\text { Lag0 }\end{array}$ & $\begin{array}{l}\text { ALL } \\
\text { Lag1 }\end{array}$ & $\begin{array}{l}\text { ALL } \\
\text { Lag2 }\end{array}$ & $\begin{array}{l}\text { North } \\
\text { Lag0 }\end{array}$ & $\begin{array}{l}\text { North } \\
\text { Lag1 }\end{array}$ & $\begin{array}{l}\text { North } \\
\text { Lag2 }\end{array}$ & $\begin{array}{l}\text { South } \\
\text { Lag0 }\end{array}$ & $\begin{array}{l}\text { South } \\
\text { Lag1 }\end{array}$ & $\begin{array}{l}\text { South } \\
\text { Lag2 }\end{array}$ & $\begin{array}{l}\text { East } \\
\text { Lag0 }\end{array}$ & $\begin{array}{l}\text { East } \\
\text { Lag1 }\end{array}$ & $\begin{array}{l}\text { East } \\
\text { Lag2 }\end{array}$ & $\begin{array}{l}\text { West } \\
\text { Lag0 }\end{array}$ \\
\hline Betula & 0.15 & 0.25 & $0.12 *$ & & & & $0.13 *$ & $0.12^{*}$ & $0.15^{*}$ & & 0.16 & 0.15 & \\
\hline LBetu & 0.23 & 0.26 & & 0.15 & $0.15^{*}$ & & & 0.16 & & & 0.16 & & 0.16 \\
\hline Ozone & & 0.15 & & 0.12 & 0.14 & & & & & & & & \\
\hline $\mathrm{PM}_{2.5}$ & $-0.13 *$ & & & & & & & & & & & & \\
\hline AQHI & & & & & & & & 0.15 & & & $0.15^{*}$ & & \\
\hline$T$ & -0.12 & -0.13 & -0.17 & & & & & & & & & & \\
\hline$T_{\mathrm{d}}$ & -0.12 & -0.19 & -0.21 & & -0.15 & -0.15 & & & & & & & \\
\hline WS & & & & & & & & & & & & & $-0.11^{*}$ \\
\hline Press & & & & & & & & 0.14 & $0.11 *$ & $0.11 *$ & $0.14^{*}$ & $0.11 *$ & \\
\hline
\end{tabular}


Table 4 Pearson's coefficient (correlation matrix) between the daily total count of asthma hospitalization and environmental parameters. Betula stands for daily birch pollen count, LBetu logarithm of Betula daily count, Ozone daily maximum surface concentration, $\mathrm{PM}_{2.5}$ daily maximum surface concentration of fine particulate matter, AQHI daily maximum of the Air Quality Health Index (3-h moving average), T daily maximum temperature, $T_{d}$ mean afternoon dew point temperature, WS mid-afternoon wind speed, Press mid-afternoon atmospheric pressure. By weather group: $\mathrm{C} 1$ : weather types 7,9 , and 12 only $(N=42), \mathrm{C} 2$ : all weather types excluding $\mathrm{C} 1(N=201), \mathrm{C} 3$ : all weather types except 2, 5, 8 , and $11(N=165), C 4$ : weather types with warm temperatures: $1,2,3,9$, 10 , and $12(N=74)$. ${ }^{a}$ all sectors, ${ }^{\mathrm{n}}$ Center-north, ${ }^{\mathrm{s}}$ Center-south, ${ }^{\mathrm{e}}$ East, ${ }^{\mathrm{w}}$ West of Montreal Island. No significant correlations were found beyond Lag2 and therefore not shown. $p<0.05$ unless otherwise stated, $* 0.05 \leq p \leq 0.10$. Empty entries in the table means no significant correlation (i.e., $p>0.1$ )

\begin{tabular}{|c|c|c|c|c|c|c|c|c|c|c|c|c|}
\hline & $\begin{array}{l}\text { C1 } \\
\text { Lag0 }\end{array}$ & $\begin{array}{l}\text { C1 } \\
\text { Lag1 }\end{array}$ & $\begin{array}{l}\text { C1 } \\
\text { Lag2 }\end{array}$ & $\begin{array}{l}\mathrm{C} 2 \\
\operatorname{Lag} 0\end{array}$ & $\begin{array}{l}\text { C2 } \\
\text { Lag1 }\end{array}$ & $\begin{array}{l}\mathrm{C} 2 \\
\mathrm{Lag} 2\end{array}$ & $\begin{array}{l}\text { C3 } \\
\text { Lag0 }\end{array}$ & $\begin{array}{l}\text { C3 } \\
\text { Lag1 }\end{array}$ & $\begin{array}{l}\text { C3 } \\
\text { Lag2 }\end{array}$ & $\begin{array}{l}\text { C4 } \\
\text { Lag0 }\end{array}$ & $\begin{array}{l}\text { C4 } \\
\text { Lag1 }\end{array}$ & $\begin{array}{l}\text { C4 } \\
\text { Lag2 }\end{array}$ \\
\hline Betula & & $0.28^{* \mathrm{w}}$ & & $0.20^{\mathrm{w}}$ & & & $0.15^{*^{\mathrm{a}}}$ & $0.27^{\mathrm{a}}$ & $0.16^{\mathrm{s}}$ & $0.19^{\mathrm{s}}$ & & \\
\hline LBetu & $0.40^{\mathrm{a}}$ & $0.41^{*^{\mathrm{a}}}$ & & $0.20^{\mathrm{w}}$ & $0.17^{\mathrm{a}}$ & & $0.27^{\mathrm{a}}$ & $0.28^{\mathrm{a}}$ & & $0.22 *^{\mathrm{n}}$ & $0.19^{*^{\mathrm{a}}}$ & \\
\hline Ozone & & $0.41^{\mathrm{n}}$ & & & & & & $0.15^{*^{\mathrm{n}}}$ & & $-0.18^{*^{\mathrm{a}}}$ & $0.17 *^{\mathrm{n}}$ & \\
\hline $\mathrm{PM}_{2.5}$ & & $0.39^{\mathrm{s}}$ & & $-0.16^{\mathrm{a}}$ & & $-0.14^{* \mathrm{a}}$ & & & & & & \\
\hline AQHI & $0.37 *^{\mathrm{n}}$ & $0.53^{\mathrm{n}}$ & & & $0.14 *^{\mathrm{s}}$ & & & & & & $0.22^{\mathrm{s}}$ & \\
\hline$T$ & & & $-0.29^{* \mathrm{~s}}$ & $-0.19^{\mathrm{a}}$ & $-0.19^{\mathrm{a}}$ & & $-0.16^{\mathrm{a}}$ & $-0.19^{\mathrm{a}}$ & $-0.22^{\mathrm{a}}$ & & & \\
\hline $\mathrm{Td}$ & & & $-0.26^{* \mathrm{a}}$ & $-0.19^{\mathrm{a}}$ & $-0.22^{\mathrm{a}}$ & & $-0.14^{* \mathrm{a}}$ & & $-0.19^{\mathrm{a}}$ & & & \\
\hline WS & $0.27 * \mathrm{w}$ & $-0.32^{\mathrm{n}}$ & & $-0.17^{\mathrm{w}}$ & & & $0.14^{* \mathrm{n}}$ & $0.17^{\mathrm{s}}$ & & $-0.16^{*^{\mathrm{a}}}$ & $0.29^{\mathrm{s}}$ & $-0.17^{* \mathrm{~s}}$ \\
\hline Press & & & $0.29 *^{\mathrm{a}}$ & & & & & & & $0.17 *^{\mathrm{n}}$ & & \\
\hline
\end{tabular}

found in a specific group of weather types (group C1: i.e., weather types 7, 9, and 12 lumped together). In this group of weather type, asthma hospitalization is the highest (in the range 3.7-3.85 according to Fig. 3a). Table 4 shows that a higher correlation (around $R=0.4, p<0.1$ ) is now found between the total number of hospitalization and the logarithm of Betula count (LBetu) for group C1 (Lag0 and Lag1). More importantly, the link between air pollution and asthma is now more robust in group $\mathrm{C} 1$ with moderate correlation between hospitalization rate and ozone ( $R=0.41, p<0.05$; in the center-north sector), $\mathrm{PM}_{2.5}$ ( $R=0.39, p<0.05$; in the center-south sector), and AQHI ( $R=0.53, p<0.05$; in the center-north sector). The highest correlation found with daily hospitalization among all variables is for AQHI of the previous day (Lag1) in the north sector of Montreal $(R=0.53, p<0.05)$ which is believed to be a causal relationship. Similarly, the AQHI of the current day (Lag0) is also important but statistically marginally significant $(R=0.37$, $0.05<p<0.10)$. The above results indicate an optimal delay effect of about 1 day (Lag1) for maximum impact of pollution on asthmatic patients (i.e., impact within about $24 \mathrm{~h}$ or so for asthma hospitalization). Note finally that a moderate negative correlation $(R=-0.29, p<0.01)$ is also found between hospitalization daily counts and daily maximum temperature which seems to confirm again a certain degree of correlation between a sudden cooling of temperature and asthma although the exact mechanism for it is not entirely clear during the spring season.

According to a panel of expert (Landrigan et al. 2002), outdoor air pollution explains acute asthma in about $30 \%$ of the cases. In here, it was found that this proportion is apparently similar (up to about $28 \%$ of the variance explained for asthma hospitalization by AQHI in Montreal, see Table 4, $R=$ $0.53)$. However, it is likely that this correlation is not only due to pollution but also due to synergy between pollen-pollution- weather type considering that such high correlation occurs only in the center of the city (high traffic) and in C1 weather situations (situation likely favorable to pollen-pollutant synergy). A similar conclusion was reached by Rosas et al. (1998) in Mexico City who pointed out that most studies have ignored important confounding factors such as aeroallergens and interaction with pollution in the analysis of asthma related to environmental factors.

The coefficients of correlation are now re-computed for all meteorological classes but excluding classes of the group $\mathrm{C} 1$ (i.e., group $\mathrm{C} 2, \mathrm{C} 3$, and $\mathrm{C} 4$ ). The results (see Table 4 under group $\mathrm{C} 2, \mathrm{C} 3$, and $\mathrm{C} 4$, respectively) show that even though some correlations remain significant $(p<0.05)$ or marginally significant $(0.05<p<0.10)$ between environmental variables and asthma hospitalization, the strength of the correlation is generally weaker than that of group $\mathrm{C} 1$ suggesting that some kind of synergy is acting in weather types belonging to group $\mathrm{C} 1$ and less in other groups.

\section{Higher asthma risk associated with warm fronts and trowals}

Betula pollen concentration during the spring pollen season as a predictor is better related with the frequency of hospitalization for asthma than does air pollution concentration in Montreal as seen in Table 3. Using the same classification of weather type previously presented (Table 2), we now group together warm fronts and trowals weather types (so-called group A) for the city south-center sector of Montreal (where air pollution is the highest) and compared with all other remaining weather types in the same sector (which forms group B, i.e., all other meteorological situations). Note that the pollen load is not considered as a confounder here given that the 
pollen load is similar within different sectors of the city center (due to very little birch pollen sources in Montreal). The result found is that the daily average hospitalization counts in the two groups were significantly different $(p=0.0008)$ under such stratification (Fig. 4a). Higher hospitalization count was found in the weather group A with an average of 3.78 hospitalizations per day (CI 95\% 2.95-4.61) as compared with an average of 2.49 (CI 95\% 2.37-2.71) for weather group B. This indicates that the two weather types associated with group A are more prone to asthma crisis in Montreal than other meteorological situation grouped together (group B) during the Betula pollen season. Figure $4 \mathrm{~b}$ suggests that ozone is also higher in group A versus group B $(p=0.075$, i.e., marginally significant). Similarly, Fig. $4 c$ shows that $\mathrm{PM}_{2.5}$ is higher as well in group A $(p=0.045)$. Finally, on Fig. 4d the logarithm of pollen count load is also higher in group A as well $(p<0.05)$. Overall, these results suggest that ozone, fine particulate matter, and allergenic pollen could contribute to increase asthma in group A (likely as a form of synergy). Supplementary material S3 shows result and tests of significance for interaction between environmental variables using procedure GLM (generalized liner models, SAS $($ ). Among significant interactions $(p<0.05)$, we find on many occasions combinations of weather type (classmet), ozone (ozoclass), $\mathrm{PM}_{2.5}$ (pmclass), and pollen class (betclass), and their lag (previous day class: i.e., lclassmet, lozoclass, lpmclass, lbetclass). Results indicate many potential interactions (or synergy between hospitalization count versus environmental factors) which are significant and cannot be ignored. Moreover, when the weather types prone to synergy are removed (weather types 7, 9, and 12), no significant interaction were found $(p>0.10)$. This confirms stronger synergy in the latter weather types.

The best predictor of asthma hospitalization is the air pollution (AQHI) according to Table 4 . The best second predictor is Betula pollen concentration. The latter relationship is not intuitive since pollen grains are of too large dimension to reach the lower airways where asthmatic reactions occur (Taylor et al. 2004). Pollen is known to cause rhinitis and conjunctivitis but its role in asthma is controversial (EPA 2008). However, respirable-sized particles released by pollen grain rupture have been detected in the atmosphere especially after rainfall (Schappi et al. 1997; Puc et al. 2016; Chathurika et al. 2017) or associated with wind-induced mechanical rupture (Visez et al. 2015). Wozniak et al. (2018) have provided modeling equations for pollen rupture in rain situation. Rupture of pollen grain producing a release of respirable bio-aerosols is highly consistent with our results (Fig. 3a) which show that warm front, occluded front (trowal), and ridge of high pressure meteorological situations were the most often encountered weather categories with uncontrolled asthma (requiring hospitalization) in Montreal during the birch tree pollen season (spring 20062008). We report here that in the context of this research, the use of conventional methods using classical statistics (without stratification into meteorological classes as presented in Table 3) has failed to establish any robust connection between environmental variables and asthma hospitalization. Only weak correlation $(R<0.3)$ appears between pollen count and asthma hospitalization and very low coefficient of correlation between ozone, $\mathrm{PM}_{2.5}$, or $\mathrm{AQHI}$ and hospitalization are noted. Moreover, unrealistic negative correlation was found between fine particulate matter $\left(\mathrm{PM}_{2.5}\right)$ and asthma hospitalization (Table 3) which is unlikely from a biological perspective. Similar negative correlation with air pollutants has also been obtained in Israel between emergency room visits of asthmatic children and ozone (Garty et al. 1998) the latter is believed to be due to uncontrolled weather confounding factors and could be explained by the Simpson's paradox. ${ }^{5}$ With meteorological stratification into groups of weather types (such as in Table 4) robust and moderate correlations $(R>0.3, p<0.05)$ start appearing between air pollution and asthma hospitalization for certain weather situations (i.e., group $\mathrm{C} 1$ ) including positive correlation with $\mathrm{PM}_{2.5}$ and much higher correlation with ozone than previously found. Note that in the eastern sector of Montreal (industrial sector E in Fig. 1), according to Table 4, no significant correlation was found with any environmental factors in weather situations $\mathrm{C} 1, \mathrm{C} 2, \mathrm{C} 3$, or $\mathrm{C} 4$ despite higher levels of sulfur dioxide usually found in this sector of the city (Ville de Montréal 2015). In another study, absence of association between asthma emergency visits and sulfur dioxide was also reported for the region of Quebec City (Lajoie et al. 1994). According to Behrendt and Becker (2001) and de Weger et al. (2013), in presence of pollen, curiously enough sulfur dioxide seems to have a protective effect which would reduce the probability of pollen rupture (likely due to its high $\mathrm{pH}$ ) therefore diminishing the risk of liberation of allergenic bio-aerosols and asthma attack. Finally, although spores could exacerbate asthma, its impact is not discussed here since the highest activity of spores does not occur in spring but rather in summer and fall in Montreal (see https://theweathernetwork.com/Spores).

Frontal asthma: a new hypothesis

For allergy sufferers, it is important to know under which meteorological condition the health risk is the highest. One might intuitively think that a higher number of hospitalization probably happens on days with high pollen counts and/or smog situation. However, the reality is much more complex. Despite high level of asthma hospitalization in weather type 12 (warm front, Fig. 3a) pollen grain count is low (see Fig. 3c) with modest air pollution found (see Fig. 3b). In fact, the sudden rise of absolute humidity, intermittent convective rainfall, convergence of aerosols, and likely increase of electrical field

\footnotetext{
${ }^{5}$ The Simpson's paradox is a common problem when analyzing data and occurs when a confounding factor is present. In extreme cases, it can reverse the sign of the correlation when the confounding is properly controlled or its impact eliminated (Julious and Mullee 1994).
} 
Fig. 4 a Daily average number of hospitalization in Montreal due to asthma in situation of warm front or trowal (weather types of group A) as compared with all other remaining meteorological situations (group B) during the Birch pollen season. With warm and occluded fronts, an increase of $52 \%$ asthma hospitalization is noted. Differences are statistically significant between group A (warm front and trowal: prone to pollen rupture) and group B (less prone to pollen rupture), $\mathbf{b}$ idem but for ozone, $\mathbf{c}$ idem for PM2.5, d idem for log of pollen count. The vertical gray rectangles indicate the interval of confidence to $95 \%$
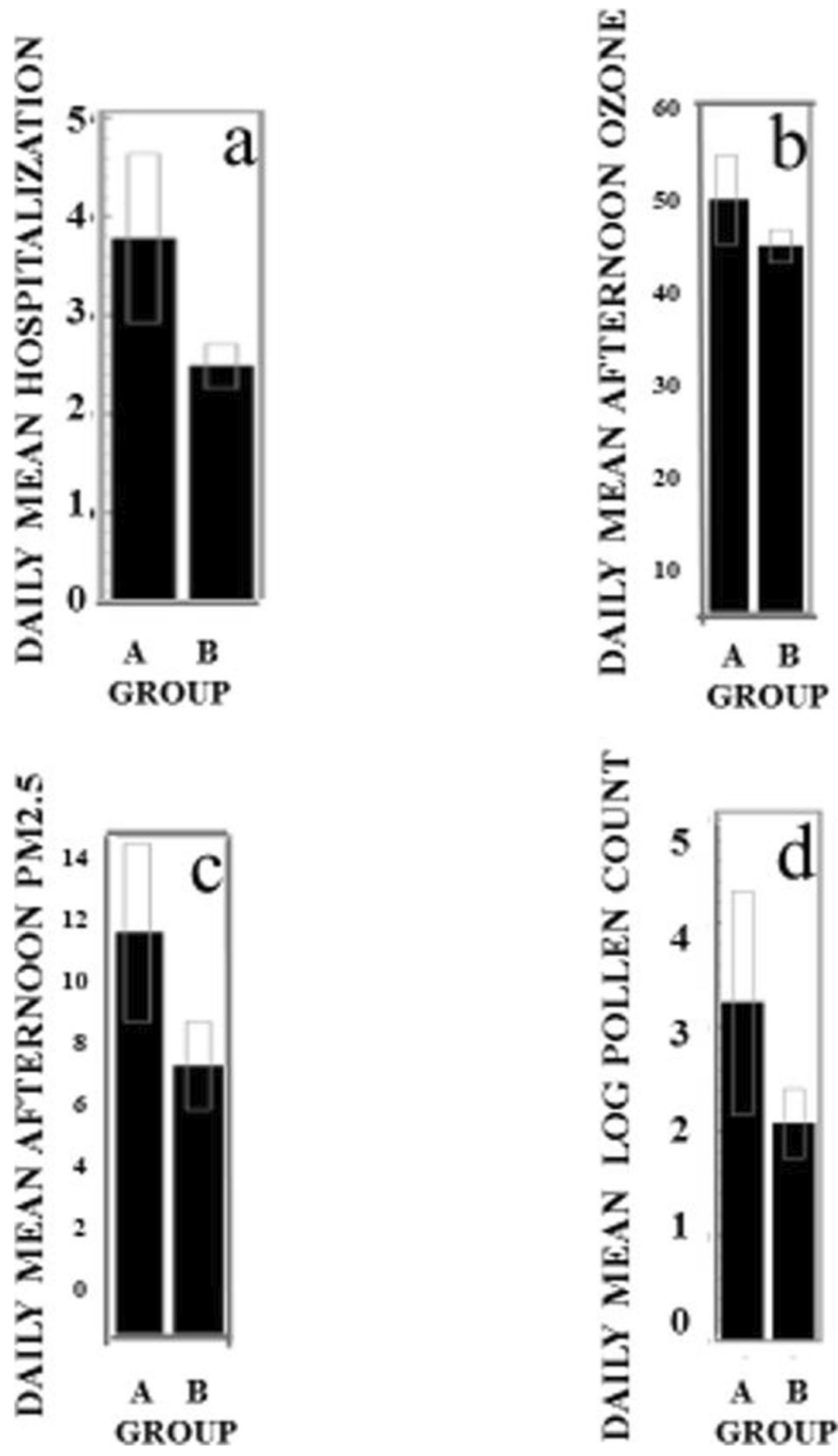

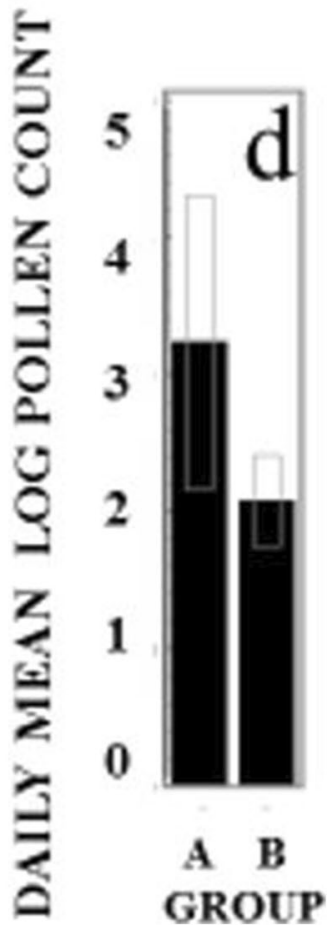

accompanying active fronts would considerably increase the likelihood of pollen rupture and therefore liberation of small allergens inside pollen carriers (Bet $v 1, v 2$, and $v 4$ in the case of birch) based on numerous laboratory experiments (see literature review in Introduction). It is suggested here that it is for these reasons why atmospheric abrupt changes (often frontal situation) tend to augment asthma risk as noted in the hospital communities although rarely addressed in peer-review literature. One study by Mireku et al. (2009) showed that a rapid increase of humidity or temperature (such as found associated with warm fronts or trowal during the birch pollen season) was associated with asthma rise among children. Overall, based on the evidence presented above, a new concept so-called frontal asthma is now proposed which offers a plausible explanation to the rise of asthma hospitalization in active frontal or any other abrupt weather changes (trowals, squall lines, thunderstorms, 
etc.). Figure 5 illustrates the new concept (here for the case of a warm front). It is well known that a trough of barometric pressure usually accompanies fronts causing wind convergence (Environment Canada 1996) leading to accumulation of primary aerosols, pollen, and spores near the front. Frontal clouds and precipitation would humidify the pollen to the point of rupture and electrical field higher in convective precipitation (if any) would possibly enhance further the likelihood of rupture. Given the similarity with the phenomenon of thunderstorm asthma (see D'Amato et al. 2015; D'Amato et al. 2016), it is suggested here that the latter could be a special case of frontal asthma but at a different spatiotemporal scale (i.e., at local scale for the former) instead of at synoptic scale (for the latter as depicted in Fig. 5). In fact, the sudden rise of asthma cases noted in different parts of the world (D'Amato et al. 2015, D'Amato et al. 2016) is also somehow linked with a frontal system at the local scale (i.e., thunderstorm gust front or outflow). The thunderstorm outflow is a front just like synoptic front but occurring at a smaller spatial and temporal scale. ${ }^{6}$ In fact, the schematic of Fig. 5 could also be applied for a thunderstorm outflow (gust front) but with cold air pushing behind the front instead of warm air. The thunderstorm asthma phenomenon is certainly more violent and occurs when the thunderstorm gust front passes over producing epidemic asthma hospitalization as reported in London, England, and Australia (see Taylor and Jonsson 2004; Marks and Bush 2007). In both cases (synoptic front or thunderstorm gust front), the probability of pollen rupture tends to increase under enhanced electrical filed (Vaidyanathan et al. 2006; de Weger et al. 2013) particularly when it is combined with higher humidity which is also known to cause pollen rupture (Miguel et al. 2006; Zhou 2014). All the above factors combined could explain the fact that higher rate of hospitalization than average is observed in warm front passing over Montreal despite low value of pollen counts for this weather type (see Fig. 3 and Supplementary material S2). Note that cold fronts are potentially candidate for enhanced synergy as well. However, in our case, cold fronts were found not active (only wind with little or no precipitation) during the entire study period in Montreal (spring pollen season of years 2006-2008). For example, Table S3a (Supplementary material S2) shows an example of an inactive cold front (on May 27, 2006).

\section{Conclusions}

This research has addressed the complex interaction between environmental conditions and asthma. Overall, warm front, trowal, and ridge of high pressure weather types were the most

\footnotetext{
${ }^{6}$ According to Fujita (1986), thunderstorm gust front has a scale of 10-300 $\mathrm{km}$, a duration of 0.5 to 6 hours and maximum wind speed of $35 \mathrm{~m} / \mathrm{s}$ whereas a warm front has scale of 300-1000 km, duration of 1 to 3 days and maximum wind speed of $15 \mathrm{~m} / \mathrm{s}$. Hence, thunderstorms can be viewed as a sub-synoptic disturbance whereas a front is at synoptic scale.
}

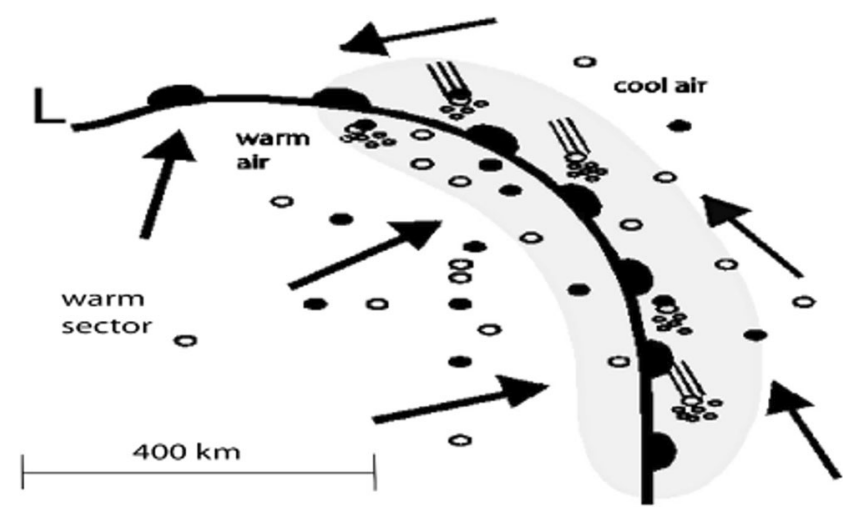

Fig. 5 Schematic concept of frontal asthma (see text for details). Black and white circles touching each other indicate a synergy pollen-pollutant (polluen) and vertical tilted lines depicts precipitation. Both factors are known to trigger pollen rupture and release of bio-aerosols (smaller white circles)

often encountered situations with uncontrolled asthma (requiring hospitalization) in Montreal during the birch tree pollen season. First, in a situation of ridge of high pressure (weather type 7), the relatively high rate of hospitalization (Fig. 3a) is explained by the fact that the airborne pollen load is higher high (Fig. 3c) due to favorable pollen emission and efficient atmospheric dispersion in this weather type (Laaidi et al. 1997). A fraction of pollen is ruptured by wind-induced mechanical impact releasing airborne allergens (Visez et al. 2015 ) in this case. On the other hand, the case of warm front (including trowal) is more complex and the frontal asthma concept (Fig. 5) has been proposed based on Figs. 3a, c and $4 \mathrm{a}-\mathrm{c}$, Supplementary material S2 (two case studies analysis) and a synthesis of many reports in the literature (e.g., Schappi et al. 1997; Taylor et al. 2004; Mireku et al. 2009; Klein et al. 2012). Our analysis used a synoptic weather type-based approach to reduce the effect of meteorological confounding factors in the analysis (minimizing variability of temperature, sunlight, dew point temperature, or relative humidity within a given weather type). Moreover, the study was restricted to only spring season to avoid confounding factors related to seasonal changes and impact of other allergenic pollen types (grass or ragweed) or molds and spores (which have peaks in summer and fall in Montreal, but have low values in the study period). In this research, it was hypothesized that active fronts may present similar environmental conditions than that of thunderstorms although less in intensity (in terms of showers, humidity, vertical lifting of particles, electrical field, convergence of pollutants and aerosols, etc.) but with fronts occurring more frequently ( 24 days of warm or occluded fronts noted during the study period and only few cases of brief thunderstorms reported ${ }^{7}$ ). In the future, we suggest that effort and studies should emphasize on measuring the counts of allergens since these tiny bio-aerosols describe better

\footnotetext{
${ }^{7}$ Thunderstorm's season usually starts after the birch pollen season in Montreal (i.e., not under the study period).
} 
exposure to allergens causing asthma than the pollen itself as pointed out by Buters et al. $(2010,2012)$. Nevertheless, the concept of frontal asthma as suggested if correct could provide a science advance since (1) it relates pollen upture likelihood with synoptic frontal meteorological conditions (wind convergence of pollutants and pollen, higher humidity and precipitation, enhanced atmospheric electrical field, barometric pressure changes), (2) it re-conciliates many observations from literature and summarizes the results of the statistical analysis presented in this research, and finally (3) it possibly generalizes and include the already known concept of thunderstorm asthma (i.e., asthma attack associated with the outflow gust front), since, in all cases, either synoptic (frontal asthma) or sub-synoptic front (thunderstorm asthma), there are sudden changes of atmospheric conditions (although more violent and sudden in the thunderstorm case). In the hospital community, it is known that sudden atmospheric changes promote asthma (Beer et al. 1991; Lajoie et al. 1994 and references therein; Mireku et al. 2009) but details are lacking relative to the weather type in which it occurs. Although this research is exploratory, it provides some evidence that some specific weather situations are more prone to asthma and likely pollen releasing allergens. Further research is needed to replicate the concept of frontal asthma to other locations and for other pollen types. However, a true validation would require the monitoring of allergens, not only that of pollen concentrations.

Acknowledgements The authors would like to thank Denis Hamel from the "Institut National de Santé Publique", Gov. of Québec for providing data on asthma hospitalization and Dr. R. Pampalon for some advices.

Open Access This article is distributed under the terms of the Creative Commons Attribution 4.0 International License (http:// creativecommons.org/licenses/by/4.0/), which permits unrestricted use, distribution, and reproduction in any medium, provided you give appropriate credit to the original author(s) and the source, provide a link to the Creative Commons license, and indicate if changes were made.

\section{References}

Abou Chakra OR, Lacroix G, Sénéchal H, Thibaudon M (2010) Synergie pollen-polluants et rôle des facteurs météorologiques sur le risque de pollinose: évolution des consultations dans la région amiénoise pendant la saison pollinique 2007. Revue française d'allergologie 50: 443-449 in French

ALA (Almerican Lung Association) (2019) 'Formaldehyde'. Available at https://www.lung.org/our-initiatives/healthy-air/indoor/indoor-airpollutants/formaldehyde.html (Last accessed Aug. 1 2019)

Asgari MM, DuBois A, Asgari M, Gent J, Beckett WS (1998) Association of ambient air quality with children's lung function in urban and rural Iran. Arch Environ Health 53(3):222-230
Assaad F, Cockburn WC (1974) A seven-year study of WHO virus laboratory reports on respiratory viruses. Bull. World. Health. Organization 53:437-445

Beer S, Kannai Y, Waron M (1991) Acute exacerbation of bronchial asthma children associated with afternoon weather changes. Amer Rev Resp Dis 144:31-33

Behrendt H, Becker WM (2001) Localization, release and bioavailability of pollen allergens: the influence of environmental factors. Current Opinion in Immunology 13(6):709-715

Bergeron C, Hamid Q (2005) 'Relationship between asthma and rhinitis: epidemiologic, pathophysiologic, and therapeutic aspects'. Available at https://aacijournal.biomedcentral.com/articles/10.1186/ 1710-1492-1-2-81

Buters JT, Weichenmeier I, Ochs S, Pusch G, Kreyling W, Boere AJ, Schober W, Behrendt H (2010) The allergen Bet $v 1$ in fractions of ambient air deviates from birch pollen counts. Allergy 65:850-858

Buters JT, Thibaudon M, Smith M, Kennedy R, Rantio-Lehtimäki A, Albertinif R, Reese G, Weberg B, Galan C, Brandaoi R, Antunesi CM, Jägerd S, Bergerd U, Celenk S, Grewling L, Jackowiak B, Sauliene I, Weichenmeier I, Pusch G, Sarioglu H, Ueffing M, Behrendt H, Prank M, Sofiev M, Cecchi L, The HIALINE working group (2012) 'Release of Bet v1 from birch pollen from 5 European countries. Results from the HIALINE study', Atmos. Environ.., Vol.55, pp.496-505. Available at http://www.sciencedirect.com/ science/article/pii/S1352231012000751. Accessed 5 Sept 2019

Chan TC, Chen ML, Lin FF, Lee CH, Chinag PH, Wang DW, Chuang JH (2009) Spatio-temporal analysis of air pollution and asthma patient visits in Taipei, Taiwan. Int. J. of Health Geographics 8:126-135. https://doi.org/10.1186/I476-072X-8-26

Chathurika MR, Metwali N, Jayarathne T, Kettler J, Huang Y, Thorne PS, O'Shaughnessy PT, Stone EA (2017) Influence of rain on the abundance of bioaerosols in fine and coarse particles. Atmos. Chem. Phys 17:2459-2475. https://doi.org/10.5194/acp-17-2459-2017. Cheng

Cheng CS, Campbell M, Li Q, Li G, Auld H, Day N, Pengelly D, Gingrich S, Yap D (2007) A synoptic climatological approach to assess climatic impact on air quality in south-central Canada. Part I: historical analysis. Water Air Soil Pollution 182:131-148. https:// doi.org/10.1007/s11270-006-9327-3

Comtois P, Gagnon L (1988) Concentration pollinique et fréquence des symptômes de pollinose: une méthode pour déterminer les seuils cliniques. Revue Française d'Allergologie 28(4):279 in French

Comtois P (1996) Pollen dispersal and long distance transport: the case of thermophillic pollen in subarctic Canada. Aerobiologia 13:37-42. https://doi.org/10.1007/BF02694789

Dales RE, Cakmak S, Judek S et al (2004) Influence of outdoor aeroallergens on hospitalization for asthma in Canada. Environmental and occupational disorders. https://doi.org/10.1016/ j.jaci.2003.11.016

Dales RE, Cakmak S, Judek S, Coates F (2008) Tree pollen and hospitalization for asthma in urban Canada. Int. Arch. Allergy Immunol 146:241-247. https://doi.org/10.1159/000116360

D'Amato G, Holgate ST, Pawankar R, Ledford DK, Cecchi L, Al-Ahmad M, Al-Enezl F et al (2015) Meteorological conditions, climate change, new emerging factors, and asthma and related allergic disorders. A statement of the World Allergy Organization. World Allergy Organization Journal. https://doi.org/10.1186/s40413-0150073-0

D'Amato G, Vitale C, D'Amato M, Cecchi L, Liccardi G, Molino A, Vatrella A, Sanduzzi A, Maesano C, Annesi-Maesano I (2016) Thunderstorm-related asthma: what happens and why. Clin. Exp. Allergy 46(3):390-396

Delfino RJ, Gong H Jr, Linn WS, Pellizzari ED, Hu Y (2003) Asthma symptoms in Hispanic children and daily ambient exposures to toxic and criteria air pollutants. Environmental Health Perspectives 111(4):647-656 
de Weger, L.A., Bergmann, K.C., Rantio-Lehtimäki, A., Dahl, A., Buters, J., Déchamp, J., Belmonte, J. (2013) 'Impact of pollen', in: Sofiev, M. and Bergmann, K.C. (Eds) Allergenic pollen, a review of the production, release, distribution and health impacts, Chap. 6. Springer Science+Business Media, Dordrecht, 2013, 256 pp. ISBN 978-94-007-4880-4e-ISBN 978-94-94-007-4881-1. doi https://doi.org/10.1007/978-94-007-4881-1_6

Environnement Canada (1996) MÉTAVI. Second Edition. Government of Canada publication. Quebec region

EPA (US Environmental Protection Agency) (2008) Review of the impacts of climate variability and change on aeroallergens and their associated effects. Report EPA/600/R-06/164F. Available at www. epa.gov, (Accessed 5 March 2018)

Fujita TT (1986) 'Mesoscale classifications: their history and their application to forecasting', in Ray, P. (Ed.) Mesoscale meteorology and forecasting, American Meteorology Society, Boston. ISBN 0933876-66-1

Garcia-Mozo H, Galan C, Aira MJ et al (2002) Modelling start of oak pollen season in different climatic zones in Spain. Agricultural and Forest Meteorology 110:247-257

Garty BZ, Kosman E, Ganor E, Berger V, Garty L, Wietzen T, Waisman Y, Mimouni M, Waisl Y (1998) Emergency room visits of asthmatic children, relation to air pollution, weather, and airborne allergens. Annals of allergy, asthma and immunology 81:563-570

Gervais P (1994) Maladie asthmatique et aggression chimique. Rev. Fr. Allergol. 34(5):403-407

Grossman J (1997) One airway, one disease. Chest 111(Suppl 2):11S$16 \mathrm{~S}$

Guérin B. (1993) Pollen et allergies. Édition Allerbio, Varennes-enArgonne, France

Hebbern C, Cakmak S (2015) Synoptic weather types and aeroallergens modify the effect of air pollution on hospitalization for asthma hospitalizations in Canadian cities. Environmental pollution 204:9-16

Heidorn KC, Yap D (1986) A synoptic climatology for ozone in Southern Ontario 1976-1981. Atmospheric Environment 20:695-703

Helbig N, Vogel B, Vogel H, Fiedler F (2004) Numerical modelling of pollen dispersion on the regional scale. Aerobiologia 3:3-19

Hirst JM (1952) An automatic volumetric spore trap. Annals of Applied Biology 39:257-265

Hondula DM, Davis RE, Knight DB et al (2013) A respiratory alert model for the Shenandoah Valley Virginia USA. International J. of Biometeorology 57:91-105. https://doi.org/10.1007/s00484-0120537-7

HSC (Health Statistics Center, West Virgina Department of Health and Human Resources) (2008), Asthma hospitalizations, 1996-2006'. Statistical Brief, no. 22

Jolliffe IT (2002) Principal component analysis, 2nd ed. Springer-Verlag New-York, ISBN 0-387-9544-2

Julious SA, Mullee MA (1994) 'Confounding and Simpson's paradox'. BMJ, https://doi.org/bmj.309.69667.1480

Kestenbaum B (2009) 'Epidemiology and biostatistics: an introduction to clinical research'. Chap. 10. Springer Science+Business Media, Springer New-York, doi https://doi.org/10.1007/978-0-387-88433210

Klein T, Kukkonen J, Dahl A, Bossioli E, Baklanov A, Vik AF, Agnew P, Karatzas KD, Sofiev M (2012) Interactions of physical, chemical, and biological weather calling for an integrated approach to assessment, forecasting and communication of air quality. Ambio 41:851864. https://doi.org/10.1007/s/13280-012-0288-z

Laaidi K, Laaidi M, Besancenot JP (1997) Pollens, pollinoses et météorologie. La météorologie 20(8):41-55 in French

Laaidi M (2001) Regional variations in the pollen season of Betula in Burgundy: two models for predicting the start of the pollination. Aerobiologia 17:247-254
Laaidi M, Chinet T, Aegerter P (2011) Allergies au pollen, pollution et climat: revue de la littérature. Revue française d'allergologie 51: $622-628$

Lacroix G (2005) Allergies respiratoires, pollens et polluants. Arch. Mal. Prof. Env. 66:584-591

Lajoie P, Lebel G, Leduc R, Boulet LP, Bourbeau J, Bernard PM (1994) 'Étude sur la relation entre les visites à l'urgence des hôpitaux pour l'asthme, la qualité de l'air et les conditions météorologiques pour la Communauté urbaine de Québec (1990-1991): rapport final 1992'. Département de santé communautaire du Centre hospitalier de 1'Université Laval, Québec: ministère de l'Environnement et de la Faune, QEN/QA94-2/6. Envirodoq EN940068. Gouvernement du Québec, in French

Lamb HH (1972) 'British Isles Weather types and a register of daily sequence of circulation patterns, 1861-1971', Geophysical Memoir 116, HMSO, London, 85pp

Landrigan PJ, Schechter CB, Lipton JM, Fahrs MC, Schwartz J (2002) Environmental pollutants and disease in American children: estimates of morbidity, mortality and costs for lead poisoning, asthma cancer and developmental disabilities. Env. Health Perspec. 110(7): $721-728$

Lee CC, Sheridan SC, Lin SS (2012) Relating weather types to asthmarelated hospital admissions in New-York State. EcoHealth 9:427439

Mandrioli, P., Comtois, P., Levizzani, V. (1998) Methods in aerobiology, Pitagora Editrice, Bologna, ISBN 8-371-1043-X

Marks GB, Bush RK (2007) It's blowing in the wind: new insights into thunderstorm-related asthma. J. of Allergy Clin Immuno 120:530 532. https://doi.org/10.1016/j.jaci.2007.07.012

Miguel AG, Taylor PE, House J, Glovsky MM, Flagan RC (2006) Meteorological influences on respirable fragment release from Chinese Elm pollen. Aerosol Science and Technology 40:690-696

Mireku N, Wang Y, Ager J, Reddy RC, Baptist AP (2009) Changes in weather and the effects on pediatric asthma exacerbations. Annals Allergy Asthma Immunol. 103(3):220-224. https://doi.org/10.1016/ S1081-1206(10)60185-8

NRC (National Research Council) (1985) Epidemiology and air pollution. National Academy Press, Washington, D.C

Okuyama Y, Matsumoto K, Okochi H, Igawa M (2007) Adsorption of air pollutants on the grain surface of Japanese cedar pollen. Atmos. Env. 41:253-260

Peltre G (1998) Inter-relationship between allergenic pollens and air pollution. Allergie et Immunologie 30(10):324-326

Public Health Agency of Canada (2018) 'Report from the Canadian chronic disease surveillance system: asthma and chronic obstructive pulmonary disease (COPD) in Canada'. ISBN: 978-0-660-09274-4

Puc M, Kotrych D, Lipiec A, Rapiejko P, Siergiejko G (2016) Birch pollen grains without cytoplasmic content in the air of Szczecin and Bialystok. Alergoprofil 12(2):101-105

Rantio-Lehtimäki A, Viander M, Koivikko A (1994) Airborne birch pollen antigens in different particle sizes. Clinical Experimental Allergy 24:23-28

Robichaud A, Bertrand N (1993) 'Analyse des niveaux d'ozone troposphérique à la station forestière de Duschenay (Québec) Bilan des années 1988 à 1991', Pollution Atmosphérique. Oct-Déc. 1993 pp. $72-85$, in French. Available at http://lodel.irevues.inist.fr/ pollution-atmospherique/index.php?id=4297

Robichaud A, Comtois P (2017) Statistical modelling, forecasting and time series analysis of birch phenology in Montreal, Canada. Aerobiologia. https://doi.org/10.1007/s10453-017-9488-0

Robichaud A. (2019) Synergie entre la pollution anthropique et biologique et impacts sur la santé respiratoire au Québec durant le printemps. Pollution atmospherique. Available at http://lodel. irevues.inist.fr/pollution-atmospherique/index.php?id=6766. Accessed 5 Sept 2019 
Rosas I, McCartney HA, Payne RW, Calderón C, Lacey J, Chapela R et al (1998) Analysis of the relationship between environmental factors (aeroallergens, air pollution and weather) and asthma emergency admissions to a hospital in Mexico City. Allergy 53:394-401

SAS® Institute Inc (1989) SAS/STAT and SAS/ETS user's guide, version 6, fourth edition, volume 2, Cary, NC, USA.: SAS Institute

SAS® Institute Inc (2008) The GLM procedure (Book Excerpt). SAS/ STAT9.2 Cary, NC, USA.: SAS Institute

Schappi GF, Suphioglu C, Taylor PE, Knox RB (1997) Concentrations of the major birch tree allergen Bet $v 1$ in pollen and respirable fine particles in the atmosphere. Journal of Allergy and Clinical Immunology 100:656-661

Sedghy F, Varasteh A-R, Sankia M, Moghadam M (2018) Interaction between air pollutants and pollen grains: the role on the rising trend in allergy. Rep. Biochem. Mo. Biol. 6(2):219-224

Sheridan SC (2002) The redevelopment of a weather-type classification scheme for North America. Int. J. Climatol. 22:51-68

Schultz DM, Vaughan G (2011) Occluded fronts and the occlusion process: a fresh look at conventional wisdom. Bulletin of American Meteorology 92(4):443-466

Sénéchal H, Visez N, Charpin D, Shahali Y, Peltre G, Biolley JP et al (2015) A review of the effects of major atmospheric pollutants on pollen grains, pollen content and allergenicity. The Scientific World Journal. https://doi.org/10.1155/2015/9402243

Shima M, Nitta Y, Adachi M (2003) Traffic-related air pollution and respiratory symptoms in children living along trunk roads in Chiba Prefecture', Japan. J. Epidemiol. 13:108-119

Sofiev M, Siljamo P, Ranta H, Rantio-Lehtimäki A (2006) Towards numerical forecasting of long-range air transport of birch pollen: theoretical considerations and a feasibility study. Int J Biometeorol 50: 392-402. https://doi.org/10.1007/s00484-006-0027-x

Sofiev M, Bergmann KC (2013) Allergenic pollen. A review of the production, release, distribution and health impacts. Springer Science+ Business Media, Dordrecht, ISBN978-94-007-4880-4e-ISBN 97894-94-007-4881-1

Stieb DM, Burnett RT, Smith-Dorion M et al (2008) A new multipollutant, no-threshold air quality health index based on short-term associations observed in daily time-series analyses. J. Air Waste Manage. Assoc. https://doi.org/10.3155/1047-3289,58. 3,435

Tamburlini G. (2002) Environmental hazards in speficic settings and media: an overview, in: Tamburlini, G., von Ehrenstein, O.S., Bertolini, R. (Eds) Children's health and environment: a review of evidence. A joint report from the European Environment Agency and the World Health Organization Regional Office for Europe. Chap. 2. WHO Regional Office for Europe. ISBN 92-9167-412-5
Taylor PE, Jonsson H (2004) Thunderstorm asthma. Curr. Allergy Asthma Rep. 4(5):409-413

Taylor PE, Flagan RC, Miguel AG et al (2004) Birch pollen rupture and the release of aerosols of respirable allergens. Clin. Exp. Allergy 34: $1591-1596$

Traidl-Hoffmann C, Kasche A, Menzel A, Jakob T, Thiel M, Ring J, Behrendt H (2003) Impact of pollen on human health: more than allergen carriers? Int. Arch. Allergy and Immunol. 131:1-13

Thibaudon M (2007) Pollen, allergies et changements climatiques. Press Therm Climat 144:117-120

Vaidyanathan V, Miguel AG, Taylor PE, Flagan RC, Glovsky MM (2006) Effects of electric fields on pollen rupture. Journal of Allergy and clinical immunology 117(2):S157 Supplement issue

Ville de Montréal (2015) Bilan environnemental 2014. Qualité de l'air à Montréal. Available at http://ville.montreal.qc.ca/pls/portal/docs/ PAGE/ENVIRO FR/MEDIA/DOCUMENTS/RSQA bilan2014 FR.pdf. (Accessed 21 May 2016)

Ville de Montréal (2019) Bilan environnemental 2018. Qualité de l'air à Montréal. Available at http://ville.montreal.qc.ca/pls/portal/docs/ PAGE/ENVIRO_FR/MEDIA/DOCUMENTS/RSQA_bilan2018 FR.pdf. (Accessed 1 August 2019)

Visez N, Chassard G, Azarkan N, Naas O, Sénéchal H, Sutra JP, Poncet P, Choël M (2015) Wind-induced mechanical rupture of birch pollen: potential implications for allergen. Journal of Aerosol Science. https://doi.org/10.1016/j.jaerosci.2015.07.005

von Ehrenstein, O.S (2002) 'Asthma, allergies and respiratory health. In: Tamburlini G, von Ehrenstein OS, Bertolini R (eds) Children's health and environment: a review of evidence'. A joint report from the European Environment Agency and the World Health Organization Regional Office for Europe. Chap. 3. WHO Regional Office for Europe. ISBN 92-9167-412-5

Wallin JE, Segerstrom U, Rosenhall L et al (1991) Allergic symptoms caused by long-distance transported birch pollen. Grana 30:265-268

White MC, Etzel RA, Wilcox WD, Lloyd C (1994) Exacerbations of childhood asthma and ozone pollution in Atlanta; epidemiology study. Environmental Research 65(1):56-68. https://doi.org/10. 1006/enrs.1994.1021

Wozniak MC, Solomon F, Steiner AL (2018) Pollen rupture and its impact on precipitation in clean continental conditions. Geophysical Research Letters. https://doi.org/10.1029/2018GL077692

Zhou Q (2014) Relative humidity induced plant pollen grain rupture and conceptual model development, Master's thesis. Washington State University, USA

Publisher's note Springer Nature remains neutral with regard to jurisdictional claims in published maps and institutional affiliations. 